\title{
JUDICIALIZAÇÃO DA MEDICINA: DIÁLOGOS ENTRE OS PODERES MÉDICO E JUDICIÁRIO
}

\author{
JUDICIALIZATION OF MEDICINE: DIALOGUES BETWEEN THE \\ MEDICAL AND JUDICIAL POWERS
}

Camila Vasconcelos

\section{RESUMO}

Trata-se de escrita teórica que partiu da premissa de judicialização na relação médico-paciente como perspectiva litigante excessiva, apontando uma substituição de poderes tendo em vista uma possível falência no âmbito dialógico entre os sujeitos, conforme a noção sponvilliana de poder. Para tanto, abordou os sistemas de dominação foucaultianos em diálogo com outros autores, identificando contextos de pacientes e, ainda, de médicos como sujeitos também passíveis de identificarem-se com o âmbito de menor poder, quando em perspectivas institucionais e judicantes. Concluiu pela verificação da apontada falência dialógica, concretizada pela manutenção dos sistemas de dominação e agravada pela dificultosa realização de direitos fundamentais na prática cotidiana, compreendendo que o poder médico vive, neste momento, uma discussão sobre a sua necessária relativização e simetria diante do início do desenvolvimento de um novo poder. Assim, a judicialização apresentou-se efetivamente como a materialização dos conflitos provenientes da assimetria na relação, sendo necessário um diálogo adequado ao esclarecimento e à absorção de informações prévias à conduta médica responsável.

Palavras-chaves: Judicialização. Poder. Relação Médico-Paciente.

\section{ABSTRACT}

It is a theoretical writing that started from the premise of judicialization in the doctor-patient relationship as an excessive litigant perspective, pointing to a substitution of powers in view of a possible bankruptcy in the dialogical scope between the subjects, according to the sponvillian notion of power. In order to do so, it approached the Foucauldian systems of domination in dialogue with 
other authors, identifying patient contexts and, also, doctors as subjects also able to identify themselves with the scope of lesser power, when in institutional and judicial perspectives. It concluded by the verification of the indicated dialogical bankruptcy, materialized by the maintenance of the systems of domination and aggravated by the difficult realization of fundamental rights in the daily practice, understanding that the medical power lives, at this moment, a discussion about its necessary relativization and symmetry before the beginning of the development of a new power. Thus, the judicialization was effectively presented as the materialization of the conflicts arising from the asymmetry in the relationship, and a proper dialogue is required to clarify and absorb information prior to responsible medical conduct.

Key-words: Judicialization. Power. Physician-Patient Relations.

\section{INTRODUÇÃO: A ASSIMETRIA PROTAGONISTA DE CONFLI- TOS EM ÂMBITO JUDICIAL}

0 poder médico de superioridade decisional na assistência ao paciente fez-se presente no decurso da história ocidental da medicina, especialmente a partir dos contornos técnico-científicos e biotecnológicos. A despeito de significar uma evolução em perspectivas diagnósticas, o ingresso da tecnologia na perspectiva de poder trouxe, ainda, contextos de possíveis distanciamentos na relação com o paciente, quando apresentada em detrimento do diálogo aprofundado entre os sujeitos.

0 fato é que o poder médico se manteve sob um controle advindo do conhecimento produzido em seu discurso - representado pela voz médica ou da tecnologia -, o que perfez ou reforçou uma assimetria entre os sujeitos, que passou a protagonizar conflitos em âmbito judicial. Esta percepção de assimetria de poder coaduna com os estudos foucaultianos a respeito dos usos dos poderes nos meios sociais - sejam eles médicos ou judiciais -, seus aspectos históricos e circunstanciais que o relacionam à existência de um saber, que é apresentado em um dado meio através do discurso (FOUCAULT, 1979, p. 01). Mais especificamente, Foucault afirma: "o discurso não é simplesmente aquilo que traduz as lutas ou os sistemas de dominação, mas aquilo por que, pelo que se luta, o poder do qual nos queremos apoderar" (FOUCAULT, 2009, p. 10). 
É neste sentido, e em uma interpretação detida, que este estudo se desenvolve, compreendendo ser possível observar-se a existência de um poder médico nas relações com os pacientes, que se destaca no decurso do tempo, ainda que não signifique a inexistência de dificuldades a serem enfrentadas por estes mesmos médicos, tal como se verá a seguir, especialmente em um contexto de judicialização. É que os sistemas de dominação, que toma a todos, podem ser identificados em diversas relações, sejam elas pessoais ou institucionais, de maneira que aos médicos também é possível identificar-se com o âmbito de menor poder.

De todo modo, para um estudo com enfoque na relação intersubjetiva entre médicos e pacientes, seus poderes e consequentes abordagens judiciais, faz-se necessário compreender, portanto, conceitos que demonstram a efetiva hierarquização dos discursos e o dificultoso diálogo simétrico entre os sujeitos, potencializadores no surgimento de conflitos.

\section{DISCURSOS NA PRÁTICA MÉDICA SEGUNDO UMA PERS- PECTIVA FOUCAULTIANA}

Em sua obra "A Ordem do Discurso"1, originada a partir de um pronunciamento feito no Collège de France em 1970, Michel Foucault discute a relação entre "poder" e "discurso" a partir da hipótese de que

[...] em toda sociedade a produção do discurso é ao mesmo tempo controlada, selecionada, organizada e redistribuída por certo número de procedimentos que têm por função conjurar seus poderes e perigos, dominar seu acontecimento aleatório, esquivar sua pesada e temível materialidade (FOUCAULT, 2009, p. 8-9).

Nesse texto, o autor discorre sobre o "discurso", conceituando o que aponta como "procedimentos", que aclaram ao leitor os modos como os controles e as exclusões são exercidos. Segundo explica, os procedimentos, por vezes, são "externos", quando provindos do meio social, e, por outras vezes, "internos", quando exercidos no próprio discurso, como uma espécie de coerção interna. Dentre os procedimentos de controle e 
exclusão "externos", importante observar-se a "interdição", especialmente aquela sob a forma do que o autor denominou de "direito privilegiado ou exclusivo do sujeito que fala" (FOUCAULT, 2009, p. 9), em que, excluindo o não portador do privilégio, apresenta limitações à externalização de determinados assuntos em algumas circunstâncias sociais: "sabe-se bem que não se tem o direito de dizer tudo, que não se pode falar tudo em qualquer circunstância, que qualquer um, enfim, não pode falar de qualquer coisa" (FOUCAULT, 2009, p. 9).

Esta circunstância pode ser identificada como o âmbito da relação médico-paciente, na medida em que é percebida como campo em que se desenvolve a cerimônia do cuidado médico (DANTAS FILHO, 2009) sobre o corpo enfermo, e a partir da explanação de conhecimentos e discursos médicos não pertencentes às esferas do leigo. 0 diálogo na relação, a exemplo de como traz Molière alegoricamente em "O Doente Imaginário" (MOLIÈRE, 2003, p. 125), é capaz de confirmar a hierarquia pela via do conhecimento dito, pronunciado, que resvala na interdição da palavra ao não conhecedor do primordial assunto observado naquele contexto.

Esta percepção direciona-se para o procedimento de controle e exclusão que Foucault denominou de "vontade de verdade", destacado por ele dentre os demais procedimentos externos, e para o qual todos os anteriores trabalhados também se direcionam, retomando-o (FOUCAULT, 2009 , p. 19). Para o autor, esta vontade de verdade apresenta-se como a “oposição do verdadeiro e do falso" (FOUCAULT, 2009, p. 13), apoiada em um suporte institucional, e destaca o papel do conhecimento científico neste contexto. Segundo explica, esta oposição tende a exercer uma pressão sobre os demais discursos no meio social, verificada enquanto um poder de coerção, de forma que apenas são legitimadas e tomadas como admissíveis as perspectivas institucionalizadas, sobretudo cientificamente.

Isto significa que a vontade de verdade é organizada e é reconduzida "pelo modo como o saber é aplicado em uma sociedade, como é valorizado, distribuído, repartido e de certo modo atribuído" (FOUCAULT, 2009, p.17). Então, para ser verdadeiro na relação médico-paciente, o discurso "deve" buscar apoio no alicerce institucional científico (FOUCAULT, 2009, p. 17-18), observação esta que nos remonta à segunda noção foucaultiana que demonstra a possibilidade de hierarquização: 
Voltemos um pouco atrás: por volta do século XVI e do século XVII (na Inglaterra, sobretudo), apareceu uma vontade de saber que, antecipando-se a seus conteúdos atuais, desenhava planos de objetos possíveis, observáveis, mensuráveis, classificáveis; uma vontade de saber que impunha ao sujeito cognoscente (e de certa forma antes de qualquer experiência) certa posição, certo olhar e certa função (ver, em vez de ler, verificar, em vez de comentar); uma vontade de saber que prescrevia (e de um modo mais geral do que qualquer instrumento determinado) o nível técnico do qual deveriam investir-se os conhecimentos para serem verificáveis e úteis (FOUCAULT, 2009, p. 21).

Ao desconhecer as informações médicas, cabe ao paciente retomar os conhecimentos fáticos de seu cotidiano, o que serve como elemento de informação nem sempre percebido como essencial e útil ao diálogo. Isto porque pode ser posto, na conjuntura do discurso, como possivelmente não "verdadeiro" segundo os moldes científicos. Há, também, os procedimentos de controle e exclusão "internos", "visto que são os discursos eles mesmos que exercem seu próprio controle" (FOUCAULT, 2009, p. 17-18), que servem à percepção de hierarquização na relação médico-paciente. 0 primeiro é o "comentário":

[...] pode-se supor que há, muito regularmente nas sociedades, uma espécie de desnivelamento entre os discursos: os discursos que "se dizem" no correr dos dias e das trocas, e que passam como o ato mesmo que os pronunciou; e os discursos que estão na origem de certo número de atos novos de fala que os retomam, os transformam ou falam deles, ou seja, os discursos que, indefinidamente, para além de sua formulação, são ditos, permanecem ditos e estão ainda por dizer (FOUCAULT, 2009, p. 22).

Foucault traz o comentário como estes discursos que são ditos e que possuem um estatuto diferenciado, e exemplifica tendo-os como textos religiosos, jurídicos e outros que são considerados científicos, como os médicos. Mais uma vez, a fala do senso comum é percebida na realidade como não participante deste estatuto maior, portanto potencialmente inferiorizado no contexto do discurso da relação entre médicos e pacientes. 0 discurso médico, que reproduz o que até então a ciência toma por verdadeiro, apresenta-se como o comentário que tem na sua origem aquilo que pode ser dito, repetido e perpetuado, mesmo que até 
a sua possível infirmação por um novo saber que porventura venha a surgir posteriormente. 0 discurso do paciente, por sua vez, ainda que recorra a um conhecimento popular perpetuado, no meio científico não adquirirá o estatuto de verdadeiro para a perspectiva médica até então institucionalizada.

Atualmente, tal como se verá nas reflexões adiante, há uma busca por institucionalização de uma nova postura de prática da medicina, intitulada "humanização", em que se estimula, dentre outras atitudes, a valorização dos saberes populares, o que pretende modificar o contexto de desvalorização dos saberes diversos aos científicos, bem como enaltecer o ponto de vista participativo dos pacientes em seus tratamentos e buscas diagnósticas (SOARES; CAMARGO JUNIOR., 2007). Ainda assim, nestes mesmos tempos, é percebido o contexto de superioridade do discurso médico-científico, e mantém-se o perfil assimétrico (CAPRARA; RODRIGUES, 2004), historicamente verificado na relação.

Outro procedimento está na esfera do "autor", que é considerado complementar à percepção do comentário como controle. Este autor é posto não necessariamente como um indivíduo, mas como agrupamento dos discursos do qual é exigida uma coerência entre as suas colocações (FOUCAULT, 2009, p. 26), um fio condutor de seu raciocínio e estilo tal como rotineiramente é exposto. Deste autor, por sua vez, também é exigido que responda sobre sua identidade, sua procedência e o conteúdo de suas manifestações, prestando contas acerca do que é referido em seu nome, suas entrelinhas e dizeres expressos no mundo real (FOUCAULT, 2009, p. 27-29).

Configura-se como uma espécie de "coerção do discurso que domina as suas aparições aleatórias” (FOUCAULT, 2009, p. 37). Afinal, dele será exigida a integração com um perfil da fala, ou sobre o conteúdo de que fala. Pode-se vislumbrar novamente nesta esfera, portanto, a configuração do agrupamento do discurso médico-científico, que possui estas características de atribuição ao que é dito como discurso verdadeiro e intangível, portanto como conteúdo repetido pelos dizeres no meio social, tal qual um eco da verdade na relação com o seu paciente. Desta ideia decorre o cuidado com o que pronuncia, e como pronuncia: "aquilo que ele escreve e o que não escreve, aquilo que desenha, mesmo a título de 
rascunho provisório, como esboço da obra, e o que deixa, vai cair como conversas cotidianas" (FOUCAULT, 2009, p. 29), vai ser comentado e repetido. Sendo assim, trata-se de uma atribuição significativa, capaz de projetar sobre este discurso médico uma responsabilidade de emitir respostas exigidas, e de prestar contas a respeito do que pronunciou sob sua roupagem institucionalmente verificada (FOUCAULT, 2009, p. 27).

A respeito deste aspecto, pode-se traçar um paralelo com a crescente judicialização da medicina, que incorpora a busca pela responsabilização médica nos âmbitos ético-disciplinar e judicial. É que a percepção das normas brasileiras, atualmente, é a de que o discurso médico, falado ou escrito, tem significativa força, especialmente quando disposto em determinados documentos, pois se apresenta como capaz de emitir verdades a princípio inquestionáveis. Um exemplo são as informações médicas prestadas por meio de seus "atestados", de maneira que documentos hábeis a "atestar" são instrumentos verossímeis. Têm, mais precisamente segundo as normas brasileiras, o que se denomina "fé-pública" e "presunção de veracidade". Assim, são oponíveis a todos, até que se prove o contrário (OSELKA, 2013).

O terceiro procedimento interno é a "disciplina”, que é definida como um âmbito de domínio de objetos e métodos em que estão corporificadas as proposições consideradas "verdadeiras" (FOUCAULT, 2009, p. 30). Âmbito este mutável conforme a época histórica e as suas evoluções conceituais científicas, capazes de ensejar novas abordagens e fundamentos teóricos (FOUCAULT, 2009, p. 35), de acordo com as suas transformações. Neste sentido, todo o conteúdo externo à esfera de determinada disciplina não poderia ser considerado verdadeiro até então, embora, passados alguns anos, pudesse vir a ser confirmado, em um novo contexto daquela mesma disciplina, agora modificada. E o oposto também se torna possível: ter-se um conteúdo considerado verdadeiro, portanto capaz de se enquadrar na perspectiva disciplinar de determinada época, e verificar-se, seguidamente, como falso. Neste momento, quando infirmado por novas perspectivas, se passa a compreender que se tratava de nada mais do que um "erro disciplinado" (FOUCAULT, 2009, p. 35).

Esta característica de ordenamento por métodos que legitima a disciplina, independentemente de seu autor ou inventor, bem como este 
perfil de mutabilidade que termina por ensejar uma não repetição de enunciados fazem com que, para Foucault, a "disciplina" seja oposta aos dois procedimentos internos de exclusão, o "autor" e o "comentário". Para ele, é na disciplina que se enquadra a medicina, o que faria cair por terra a percepção até então deduzida de compreensão dos procedimentos do comentário e do autor como verificáveis no processo de hierarquização nos discursos na relação médico-paciente.

Entretanto, na medida em que se observa a medicina como campo objetivo em que se desenvolvem os estudos médicos continuamente, de outra forma também se observa a relação médico-paciente como campo subjetivo em que interagem propriamente sujeitos leigos - os pacientes - e sujeitos representantes do conhecimento - os médicos. Assim, mesmo que mutável esta objetividade, dá-se a possibilidade de alocação da temática aqui estudada nos três procedimentos, a depender da perspectiva.

Portanto, quanto aos sujeitos da relação, é possível compreender-se que vivem uma hierarquização da figura do médico em frente à figura do paciente por ser o discurso médico aquele que reúne o poder de representação da medicina, posto como repetível em determinado momento histórico-científico. Assim como, também, é possível deduzir-se esta hierarquia no discurso médico dentro do espectro do poder disciplinar da medicina, tal como campo objetivo de desenvolvimento de métodos e técnicas.

Este raciocínio poderá ser utilizado para a compreensão da desvalorização do discurso leigo, não pertencente à ordem disciplinar médica:

[...] a partir do século XIX, uma proposição não era mais médica, ela caía "fora da medicina" e adquiria valor de fantasma individual ou de crendice popular se pusesse em jogo noções a uma só vez metafóricas, qualitativas e substanciais (como as de engasgo, de líquidos esquentados ou de sólidos ressecados); ela podia e devia recorrer, em contrapartida, a noções tão igualmente metafóricas, mas construídas sobre outro modelo, funcional e fisiológico (era a irritação, a inflamação ou a degenerescência dos tecidos). Há mais ainda: para pertencer a uma disciplina uma proposição deve poder inscrever-se em certo horizonte teórico (FOUCAULT, 2009, p. 32-33).

Portanto, no que se refere à relação médico-paciente, é possível refletirmos que estes procedimentos coexistem em um espectro de exercício 
de poder que estimula, dentre outras questões, a ocorrência da assimetria. Neste sentido, apresenta a hierarquização por meio da superioridade da figura daquele que detém a "verdade", sujeito privilegiado em sua fala, repetível, em um universo disciplinador. É possível partir-se de um pressuposto, então, de que na relação entre médicos e pacientes há um poder institucionalizado, posto na ordem do discurso médico, que eleva este profissional de saúde a uma condição de sujeito determinante ou dominante de condutas sejam elas ações e omissões no contexto relacional.

Esta superioridade do discurso médico, entretanto, pode vir a ser relativizada, especialmente em contextos capazes de vulnerabilizá-lo, como o contexto da judicialização da medicina, em que a ameaça constante de se tornar réu de processos judiciais promove um permanente questionamento quanto à licitude de suas condutas, ensejando um comportamento "defensivo". Contudo, de fato, a teoria apresenta uma conceituação acerca da hierarquização no discurso capaz de auxiliar na observância da assimetria de poder no contexto vivido entre médicos e pacientes. E refletindo a hierarquização, tendo por fundamento a existência de um poder que promove a superioridade de um dos sujeitos, e colocando o poder na ordem do discurso nesta perspectiva foucaultiana, observa-se a pertinência do debate sobre a possibilidade de empoderamento do sujeito hierarquicamente inferior ${ }^{2}$.

De todo modo, a partir dessas reflexões, questiona-se sobre a possibilidade de um alargamento do diálogo, ou uma aproximação entre médicos e pacientes a partir desse diálogo até então perturbado pela hierarquia. Faz-se necessário, portanto, nesse contexto, refletir sobre o dificultoso discurso simétrico entre os sujeitos.

\section{HÁ “FALÊNCIA DO DIÁLOGO” NA MEDICINA CONTEMPO- RÂNEA?}

Um "diálogo" pode ser definido como uma conversação entre sujeitos, ou uma composição em que vozes se alternam em resposta umas às outras (MICHAELIS, 2016). Pode ser também compreendido etimologicamente como a junção das expressões gregas dia, que significa "através", 
"passagem" e logos, percebido como "razão", "palavra", "expressão", ou "fala entre duas pessoas" (CUNHA, 2010, p. 216). Assim, concebe-se o diálogo como movimento de expressões ditas, ouvidas, sentidas ou vistas, entre sujeitos, em uma perspectiva individual ou coletiva.

O que se observa em meio a estes aspectos é que para a configuração de um diálogo há, de fato, um movimento de discursos que são externalizados e internalizados, alternadamente, por sujeitos em uma fala a respeito de determinado conteúdo. Diálogo demanda, portanto, disposição dos sujeitos para este movimento, ou "tolerância", tal como aponta Abbagnano (2012, p. 275), ao conceituá-lo:

[...] o princípio do D. implica a tolerância filosófica e religiosa (v. TOLERÂNCIA), em sentido positivo e ativo, ou seja, não como resignação pela existência de outros pontos de vista, mas como reconhecimento de sua legitimidade e com boa vontade de entendê-los em suas razões.

E, sobre a “tolerância”, Abbagnano (2012, p. 962), aponta:

Na linguagem comum e às vezes na filosófica, a T. também é entendida em sentido mais amplo, abrangendo qualquer forma de liberdade, seja ela moral, política ou social. Assim entendida, identifica-se com pluralismo de valores, de grupos e de interesses na sociedade contemporânea.

Em sentido ativo, logo, esta tolerância é capaz de promover uma consideração ao ponto de vista do outro. Do mesmo modo, o que se compreende é uma necessidade de tolerância, como liberdade e respeito às diversas perspectivas para que, efetivamente, um diálogo ocorra. Ao discutir o poder do diálogo e o engajamento das pessoas comuns, Schramm estende o campo conceitual do diálogo, entendendo-o "como saber que é um dizer, mas também como um fazer que é um agir" (SCHRAMM, 2011, p. 105). Ao tomar-se este "agir" como atividade que, de algum modo, pode modificar o ambiente em que atua, temos, em um diálogo, o perpassar do conhecimento de um sujeito livre à ordem de um outro, também livre, por meio de um discurso que considera e respeita os diversos pontos de vista; além disso, como um perpassar de saber capaz de ensejar condutas potencialmente modificadoras.

Em sua reflexão, Schramm vincula três características: o conhecimento da verdade, alcançado pela mediação da razão; o fazer poiético, 
incluindo ciência, técnica e a arte; e o agir que, segundo afirma, "implica terceiros, seus desejos e interesses considerados legítimos, e os eventuais conflitos entre si" (SCHRAMM, 2011, p. 105). E ressalta um problema: "o da efetiva apreensão e/ou compreensão do outro através do diálogo" (SCHRAMM, 2011, p. 105), respondendo-o sob duas vertentes. A primeira, propondo "uma hermenêutica capaz de aceitar tanto um grau de intransparência do outro ao eu e do eu ao outro" (SCHRAMM, 2011, p. 106) considerando que "o indivíduo, formalmente autônomo, é também praticamente vinculado ao outro - e, portanto, possui uma autonomia limitada" (SCHARMM, 2011, p. 106).

A segunda, considerando que "este tipo de relação está destinado ao fracasso (...), ou seja, em substância, que não existiria um ponto de vista capaz de dar conta de todas as particularidades de cada jogo de linguagem em um diálogo" (SCHRAMM, 2011, p. 106). Porém destaca:

[...] o diálogo é um evento em que os falantes que são também agentes [...] permanecem outros entre si e, no entanto, vinculados entre si, porque cada eu precisa do outro e deve, portanto, respeitar o outro em sua diferença ou pelo menos tolerá-lo, num movimento em aberto e sempre em transformação (2011, p. 106).

Neste sentido, o autor corrobora a necessidade da tolerância para a apreensão e/ou compreensão do discurso em um diálogo e acrescenta ser assimétrica esta relação eu-outro, para o que sinaliza as visões dos filósofos Emmanuel Lévinas (1993 apud SCHRAMM, 2011, p. 106) e Hans Jonas (2006 apud SCHRAMM, 2011, p. 106) sobre o eu ser sempre devedor do outro e responsável pelo outro, respectivamente. A esta assimetria trazida pela reflexão de Schramm pode-se sinalizar o fato de que, no diálogo entre médico e paciente, podem não estar dispostas entre si as pessoas comuns a que se refere, sejam entendidas como pessoas civis em geral ou como pessoas que comungam do mesmo nível hierárquico de experiência ou conhecimento.

É que o conhecimento sobre o qual dialogam refere-se ao conhecimento sabido apenas por um dos discursantes, o que proporciona a este uma maior capacidade de discorrer e abordar o saber, o que se coaduna com a teoria foucaultiana. No âmago destes discursos, assim, está o 
poder, manifestado pela capacidade do discursante de emitir "verdades" - o saber -, que o posicionam em condição hierárquica superior, dando à relação entre sujeitos o caráter de assimétrica. De fato, e novamente, há assimetria.

Em termos ideais, minoradas as assimetrias, e por meio de um ambiente amistoso, é possível dar-se um diálogo efetivo entre estes sujeitos a partir de seus próprios pensamentos e ideias livres, propícios à conformação de acordos (BOHÓRQUEZ, 2004), dentre eles as tomadas de decisões clínicas. A história da medicina mostra a presença do diálogo como fundamental desde tempos remotos, sobretudo para a busca diagnóstica (SOURNIA, 1995). Entretanto, a história também aponta um distanciamento na conjuntura de diálogo entre os sujeitos tendo em vista a valorização, a partir do século XIX, das ferramentas tecnológicas em detrimento do discurso do paciente, tal como aponta Jean-Charles Sournia (1995, p. 251):

As últimas décadas do século XIX encetam um debate que está longe de se considerar encerrado, entre o médico que interroga o seu doente, que o examina, que mantém com ele relações de pessoa a pessoa possuindo em si mesmas um valor terapêutico, por um lado, e, por outro, o laboratório anónimo, cujos aparelhos doseiam e numeram as alterações físico-químicas. A qual dos dois deve a medicina conceder primazia?

Neste sentido, com a redução da qualidade de interação subjetiva a partir do incremento da tecnologia absorvida pelo meio médico com novos instrumentos e maquinários, o contexto da relação médico-paciente foi sendo modificado (JASPERS, 1998). Aquele vínculo anteriormente consubstanciado no diálogo ou na tentativa de alcance deste diálogo, foi invadido por elementos externos à percepção particular dos sujeitos, transformando-se. Também sobre esta perspectiva, Stanley Joel Reiser comenta (2004, p. 503):

Este avanço tecnológico reduziu a importância da narrativa do paciente. Por que os médicos deveriam adquirir minuciosamente esta narrativa e suas evidências verbais subjetivas e inverificáveis, se eles poderiam usar mais evidência objetiva que eles mesmos poderiam reunir? Com o estetoscópio, os médicos recuaram a respeito da vida dos pacientes. Eles começaram a 
avaliar os pacientes através de sinais anatômicos e fisiológicos detectados por seus instrumentos ${ }^{3}$.

A crítica, neste norte, é tecida à substituição, por novas ferramentas, do anterior contato comunicativo, em que o conhecimento a respeito da situação de saúde ou doença era explanado com proximidade, favorecendo maior contato e desenvolvimento da confiança, necessária à conformação relacional pretendida (Caprara, Franco, 1999). Isto implica a percepção de que a prática da medicina contemporânea tem promovido, paulatinamente, a redução do contato humano entre profissional e paciente, essenciais à relação (RODRIGUES, 2010).

Contudo há que se pensar contextualmente. Médicos e pacientes são coexistentes em uma mesma conjuntura de valorização da tecnologia. É possível que, diante do cotidiano da vida ocidental como um todo - consignado neste todo a medicina -, a tecnologia e a ciência tenham promovido uma rendição de discursos, que terminou por desvalorizar a perspectiva humana externa à própria tecnologia. A desvalorização da consulta médica que não resvala na prescrição de exames complementares ou de medicamentos pode ser um reflexo desta concepção. Com o objetivo de identificar a relação entre a confiança na prática médica e a necessidade de confirmação do diagnóstico por exames, Chehuen Neto et al (2007) realizaram uma pesquisa por meio de aplicação de questionário a ser respondido por usuários de um ambulatório de pronto atendimento em uma cidade brasileira, em 2007, e observaram que

Os resultados, quanto à confiança depositada nas informações dadas pelo médico em uma consulta, apontaram que $52,5 \%$ dos entrevistados confiam plenamente. Os motivos que mais suscitam confiança no paciente são o médico ouvi-lo com atenção (67,5\%) e solicitar-lhe EC Exames Clínicos $(60,5 \%)$. Esses percentuais são maiores do que aqueles relacionados às razões como perguntar seguramente $(33,0 \%)$ e/ou ao examinar no consultório $(33,5 \%)$. A postura mediante um diagnóstico médico baseado apenas na consulta, para 55,0\% dos indivíduos entrevistados, é não acreditar no diagnóstico sem a realização de exames médicos subsidiários. Quanto à possibilidade de retorno após consulta sem solicitação de EC, 76,5\% das pessoas questionadas afirmam que não retornariam, sendo que $91,5 \%$ dos entrevistados acreditam que o pedido dos mesmos seja necessário. Concluímos que, apesar do alto grau de confiança na atuação do profissional, a 
população percebe a necessidade de exames complementares como meio de confirmação da opinião médica (CHEHUEN NETO et al, 2007, p. 75).

Os dados em que pese seja necessária a realização desta pesquisa também em outras regiões brasileiras para a verificação desta perspectiva em diversos contextos culturais e socioeconômicos do país mostraram a essencialidade do uso da tecnologia para a crença no diagnóstico médico. Esta verificação enseja uma necessária contrastação de sentidos, ambos que têm a mesma consequência: o primeiro, de que o excesso de valorização da tecnologia pela medicina em detrimento do atendimento próximo ao paciente promove uma redução na relação de confiança entre os sujeitos; o segundo, de que o não uso da tecnologia como complementar à assistência médica também enseja um decréscimo na confiança de sua prática.

A tecnologização da prática médica, portanto, fez-se essencial ao meio social. Entretanto, é possível que a valorização de seu uso esteja no âmbito da complementaridade e não da substituição. É bem verdade, igualmente, que a substancial realidade de um país periférico é a de possuir maiores problemas persistentes na saúde do que propriamente emergentes (GARRAFA, 2001, p. 42). Desta maneira, é possível considerar-se reduzido o número de pacientes reclamando pelo uso de tecnologias frente ao número de pacientes que requerem, antes disso, o acesso à saúde. 0 fato é que o encontro na relação médico-paciente implica uma interação comunicativa (BOHÓRQUEZ, 2004), de forma a instalar-se uma crise a partir da sua não interação - seja pelo pouco diálogo, uso excessivo na tecnologia, ou pela pouca acessibilidade à assistência. $\mathrm{Ou}$, até mesmo, uma crise a partir da desumanização desta interação (BOHÓRQUEZ, 2004). E considerando esta desumanização como rarefação das relações interindividuais capaz de causar o aviltamento da própria relação, a consequência pode ser a inobservância de direitos constitucionalmente protegidos, ensejadora de conflitos a serem potencialmente judicializados.

Há, ainda, outra perspectiva a respeito do poder a ser trabalhada e considerada significativa, trazida por André Comte-Sponville (2008), filósofo francês que dialoga com os escritos foucaultianos. Em sua obra "Valor e Verdade: estudos cínicos", Comte-Sponville escreve sobre as 
relações entre o poder e o saber, referindo-se também à medicina. 0 autor afirma que, no momento histórico em que a medicina apenas era praticada como arte, sem o poder curativo, o seu poder impunha-se por meio de uma formalidade social que contribuía para a conformação de um imaginário de superioridade. E pondera, que nos tempos atuais ${ }^{4}$, deu-se uma substituição do poder dos adornos e cerimônias pelo poder do conhecimento. Afirma, em uma conferência, aos médicos:

A verdade é que os atavios faz tempo cederam lugar aos instrumentos. Um estetoscópio não é um penduricalho (vejo na sala alguns presentes com ar cético... digamos então que um estetoscópio não é apenas um penduricalho). Um tomógrafo não serve (ou não serve primeira e principalmente...) para impressionar a imaginação. Aqui não é mais necessário fingir. Não é mais necessário usar os atributos ornamentais de um poder imaginário. Alguma coisa deve ter mudado desde Pascal e Molière. 0 poder de vocês sem dúvida não é mais falso, pois parece que, como o rei de Pascal, vocês não têm por que se importar com a imaginação. Porque vocês têm a força? Não, justamente, e é isso que nos leva ao essencial. Se vocês não necessitam mais dos atavios de um poder imaginário, não é que vocês têm o poder real, o da força, como diz Pascal, é que vocês têm o poder do saber: a medicina, e desde há bem pouco tempo, como vocês sabem, tornou-se científica. Mas o saber é um poder? (COMTE-SPOVILLE, 2008, p. 223)

Comte-Sponville considera, de início, que o surgimento do efetivo poder médico ocorre quando a medicina se cientificiza, quando então incorpora o saber. Entretanto, em um momento seguinte, em que aprofunda a reflexão para busca do que entende ser a efetiva origem do poder, põe em dúvida esta perspectiva: “Ele vem do saber? Já não tenho tanta certeza disso!” (COMTE-SPONVILLE, 2008, p. 233).

0 autor reflete a questão, e termina por considerar que o saber é condição do poder, porém insuficiente para a sua conformação (CONTE-SPONVILLE, 2008, p. 233). Discorre exemplificando que mesmo ao maior detentor do conhecimento pode não ser dado o poder em determinadas circunstâncias:

[...] os que mais têm saber podem não ter poder nenhum, ou muito pouco (assim como um pesquisador em seu laboratório ou um residente talentosíssimo...); e que os mais poderosos (este ou aquele chefe de serviço ou 
diretor) podem ter muito menos saber do que muitos dos seus subordinados [...] (2008, p. 233).

O autor se pergunta de onde então, viria este "poder", senão do saber? E conclui pelo que considera simples e cruel: do próprio "poder" (COMTE-SPONVILLE, 2008, p. 236). Advindo, prossegue, do poder primeiro, a "força", em uma concordância com Pascal (1963 apud COMTE-SPONVILLE, 2008), que em sua obra "Pensamentos" assevera: "A força é a rainha do mundo, e não a opinião; mas, é a opinião que usa da força" (PASCAL, 2002).

Comte-Sponville refere-se à força aduzindo que, em uma democracia, é o povo o detentor, a quem é submetido o Estado de direito, esfera onde se formulam as leis, que nem sempre são "verdadeiras" tal como a ciência (COMTE-SPONVILLE, 2008, p. 240). Sendo assim, as normas produzidas pelo Estado podem vir a não refletir as perspectivas científicas. E embora destoem entre si as leis e a ciência, as primeiras ainda terão mais força, podendo vir a limitar o âmbito de atuação da segunda, ou orientar as condutas realizadas em seu propósito. 0 autor conclui:

[...] se há duas ordens distintas, portanto, a ordem do verdadeiro (o saber) e a ordem da força (o poder), a dificuldade se deve, é claro, ao fato de que sempre estamos incluídos em duas dessas ordens ao mesmo tempo: ninguém poderia escapar nem do verdadeiro nem da força. Daí uma tensão inevitável, que às vezes chega ao dilaceramento, que podemos chamar de trágico ou, mas no fundo é a mesma coisa, de responsabilidade (COMTE-SPONVILLE, 2008, p. 241).

As ordens do verdadeiro e do forte, portanto, coexistem e aplicam os seus discursos. Depositam no meio social os seus conceitos e constroem a realidade à revelia dos não-poderosos, o que enseja uma busca pela responsabilização das condutas, da qual não se deve olvidar. Mas quem seriam estes não-poderosos? 


\section{JUDICIALIZAÇÃO DA MEDICINA: DIÁLOGOS ENTRE PODE- RES E NÃO-PODERES}

No Brasil, sabe-se que o Estado de Direito atua em prol da vontade popular, que o originou, tal como traz a Constituição da República Federativa: "Art. 1… (..) Parágrafo único. Todo o poder emana do povo, que o exerce por meio de representantes eleitos ou diretamente, nos termos desta Constituição" (BRASIL, 1988). Neste sentido, a vontade maior deve ser espelhada pelos três poderes: Executivo, que rege o Estado; Legislativo, que é produtor das leis; e Judiciário, que é produtor de decisões em regras consubstanciadas nas leis.

Apesar disso, mesmo com a conformação da força popular e a eleição de suas representações com o desígnio de realizar o melhor possível ao povo, observa-se o esvaziamento da força deste mesmo povo, tendo em vista a pouca concretização cotidiana de seus direitos. Estão pouco efetivados o direito à saúde, à igualdade, ao acesso à informação, à propriedade, à segurança, à vida com dignidade, dentre outros. Embora as últimas décadas tenham trazido avanços em busca da concretização dos direitos fundamentais - com a modificação do quadro de significativa pobreza - e a concepção da perspectiva democrática seja ainda jovem no país, o contexto ainda é de procura pelo real desenvolvimento socioeconômico, o que enquadra a conjuntura brasileira no que Garrafa (2001) considerou periférica.

A partir desta percepção, é possível afirmar-se haver, no Brasil, uma espécie de "descolamento" entre o poder popular e os que dele derivaram, mantendo-se, os segundos, poderosos, em detrimento daquele que o originou, agora esvaziado. Isto significa que os não-poderosos ainda são o povo. E em uma ordem política cuja democracia torna-se rarefeita pela não garantia dos direitos fundamentais, passa-se a recorrer aos poderes do próprio Estado de Direito, agora posto como maior, contrariando-se a lógica das conquistas de lutas anteriores.

É possível que seja esta uma das conexões observadas no diálogo entre o poder médico e o poder judicial na judicialização da relação médico-paciente: a lógica da substituição diante de um discurso não sustentado. Se o discurso do paciente no contexto médico não alcança a 
sustentação esperada e tem-se o surgimento de um conflito não resolvido pelo diálogo, é possível dar-se a judicialização. A lei maior assegura, em seu art. 5o, XXXV: “a lei não excluirá da apreciação do Poder Judiciário lesão ou ameaça a direito" (BRASIL, 1988).

Sendo assim, tomando o poder médico como aquele a partir do qual são emanadas as verdades científicas e o poder judicial como aquele para o qual se recorre em busca do resguardo de direitos lesionados - ou aparentemente lesionados -, este seria um instrumento para o enfrentamento possível. Segundo Foucault, "Não constituiriam o sistema judiciário, o sistema institucional da medicina, eles também, sob certos aspectos, ao menos, tais sistemas de sujeição do discurso? ” (2009, p. 45). Sujeição, também, de um ao outro.

Trata-se de campos capazes do exercício do controle, cada qual em sua esfera. E poder-se-ia pensar no poder de controlar como força posta nas ações e nos discursos. A medicina, por seus saberes, tem o poder de controlar ou discorrer sobre o que controla o homem: o medo de sua finitude ${ }^{5}$ (FOUCAULT, 1988). 0 Poder Judiciário, da mesma forma, tem o poder de controlar ou discorrer sobre o que domina o homem em sociedade: a sua vida civil. Isto porque, legitimamente, tem ele a capacidade de determinar o cumprimento de obrigações, sejam elas as obrigações de dar, de fazer, de não fazer ou de indenizar (BRASIL, 2002). Trata-se de controle também sobre a vida, entretanto não relativo à sua finitude biológica, mas social.

Importante ressaltar que o exercício do direito de ação, reconhecido como direito de acionar o Poder Judiciário por meio do ingresso de demandas judiciais, nem sempre carrega argumentos reais, sólidos ou fundamentos concretos. Independentemente de se estar certo ou errado, tem o cidadão o direito de ingressar em juízo. Posteriormente é que se observará, após o exercício do contraditório e da ampla defesa, a quem assistia a razão.

Cumpre esclarecer que, no Brasil, fazem-se presentes dois contextos que se aproximam pela interseção da medicina, em que pese se tratar de âmbitos diversos: a "judicialização da saúde", que se refere à busca de pacientes pela realização do direito à saúde de modo amplo (OLIVEIRA, 2013), tendo por opositor o poder público ou ente privado a quem se 
dirige concessão pública (GONTIJO, 2010); e a "judicialização da medicina" que abarca as questões atinentes aos conflitos surgidos no interior da relação assistencial entre médicos e pacientes (CAMPOS; CAMARGO; NEVES, 2016).

Essa aproximação denota quão ampla está a judicialização dos problemas voltados às questões da saúde, que ora surgem ante os tribunais como dilemas éticos em âmbito constitucional a serem solucionados, ou como circunstância de busca pela realização do direito à saúde, que impacta na distribuição de recurso públicos, e ora como atinente às relações privadas, dentre elas, a relação médico-paciente. Por conta disso, em termos didáticos, é importante esta diferenciação, em busca de uma precisa compreensão das conjunturas, embora tenham o mesmo fenômeno da "judicialização" como elemento comum.

A judicialização a que se refere este estudo, portanto, deve ser compreendida como temática especificada para a relação intersubjetiva sob foco de análise. Contudo, está longe de ser uma temática com pequeno impacto, visto que é um fato crescente e que tem se ampliado, nomeadamente quando se observa este contexto sob o prisma do substancial aumento do número de demandas judiciais (ESTADÃO, 2017). São demandas indenizatórias em que pacientes e médicos figuram como autores e réus, respectivamente, e que abordam questões estritas da relação assistencial.

Em sua obra "Como nasce o direito", Francesco Carnelutti (2015) reflete, dentre outras questões, sobre o processo de construção social e aplicação das leis, observando que, além dos operadores do direito, também os cidadãos as aplicam na medida em que as tomam por base para regular suas próprias condutas, e terminam por fazer o direito, mesmo sem notar.

Os litígios, entretanto, estão sempre presentes. É que, tendo em vista a finitude dos recursos naturais, os homens guerreiam entre si, litigam. Entretanto, não podem viver no caos e necessitam viver em paz, de maneira que teorizam, pactuam normas, estabelecem contratos e unem-se passando a necessitar uns dos outros, embora, na prática, a dificuldade de eliminação desta guerra se apresente (CARNELUTTI, 2015). Neste sentido, vale ressaltar o "contrato social" rousseauniano, que defende terem os indivíduos necessitado compor acordos a fim de 
criarem sociedades e conviverem sem corromperem-se no coletivo, submetendo-se a normas:

Suponho os homens chegados a um ponto em que os obstáculos prejudiciais à sua conservação no estado de natureza vencem, por sua resistência, as forças que cada indivíduo pode empregar para manter-se nesse estado. Esse estado primitivo, então, não pode mais subsistir, e o gênero humano pereceria se não mudasse sua maneira de ser. Ora, como os homens não podem engendrar novas forças, mas somente unir e dirigir as que existem, eles não têm outro meio para se conservar senão formar por agregação uma soma de forças que possa prevalecer sobre a resistência, colocá-las em jogo por uma só motivação e fazê-las agir de comum acordo (ROUSSEAU, 2009, p. 32-33).

Neste sentido, Carnelutti (2015) afirma que, assim como os médicos são chamados quando as enfermidades se manifestam, os juristas são chamados a resolver questões não consensuadas entre sujeitos, e propõe que, tal como a educação em saúde deva ser ensinada à população, é necessário difundir ao povo noções importantes de educação jurídica, como um meio para combater problemas sociais, dentre eles, esta litigiosidade.

Sem a pretensão de adentrar na análise do possível modo de promoção desta educação, o que demandaria esforços de escrita de outro estudo, pode-se, por ora, compreender a educação jurídica como conhecimento sobre direitos e deveres constitucionais a ser absorvido pelos cidadãos, de maneira que possam construir uma conscientização sobre os limites no exercício de suas necessidades no meio social e tentar alcançar a justiça. Esta justiça, por sua vez, entendida em conformidade com o que se tem como moralmente justo, não essencialmente deve apenas encontrar-se por meio do acesso ao Poder Judiciário, mas podendo-se valer dele, quando necessário. Neste caso, são dois os possíveis contextos: o primeiro, da consensualidade, verificado diante da ausência de conflito, ou do exercício de entendimento mútuo após um anterior conflito havido entre sujeitos, que se seguiu de um consenso; e o segundo, da litigiosidade, verificada como situação em que perseveram perspectivas contrapostas, portanto divergentes, quanto ao que consideram como justo.

0 fato é que, mantendo-se o contexto de litigiosidade, o juiz "intervém para finalizar o produto semielaborado, quando os cidadãos não con- 
seguem fazê-lo sozinhos" (CARNELUTTI, 2015, p. 24). Por conseguinte, o direito pode se apresentar como instrumento pacificador (CARNELUTTI, 2015, p. 64), seja por meio do exercício voluntário de normas praticadas entre cidadãos, seja por meio da intervenção do Judiciário, quando demandado, isto é, quando instado a resolver, imparcialmente, um litígio não solucionado.

Assim é a pretensão defendida pelo exercício democrático do direito, na medida em que a Constituição Federal do Brasil assegura tanto o direito do paciente de processar o médico quando compreender haver sofrido dano, quanto o direito do médico de se defender em um devido processo, em que se respeitem as suas possibilidades de contraditório e ampla defesa, tal como dispõem os incisos constantes no artigo 5ำ que seguem: "XXXV - a lei não excluirá da apreciação do Poder Judiciário lesão ou ameaça a direito;" e "LV - aos litigantes, em processo judicial ou administrativo, e aos acusados em geral são assegurados o contraditório e ampla defesa, com os meios e recursos a ela inerentes"(BRASIL, 1988). No mesmo rumo, conforme o artigo 10 da Declaração Universal dos Direitos Humanos:

Todo ser humano tem direito, em plena igualdade, a uma audiência justa e pública por parte de um tribunal independente e imparcial, para decidir sobre seus direitos e deveres ou do fundamento de qualquer acusação criminal contra ele (UNESCO, 1948).

Entretanto, há contextos em que a procura pelo Judiciário se torna excessiva, configurando-se uma "judicialização", situação que pode ser vista sob diferentes prismas. Somado a este contexto, é importante relembrar a também referida litigiosidade (UNESCO, 1948), verificada como situação em que perseveram perspectivas contrapostas, devendo-se acrescentar, ainda, a esta, a percepção de uma cultura da litigância (LUCENA FILHO, 2012), que compreende não haver outro meio de solução de conflitos senão a abertura de processos judiciais (THEODORO JÚNIOR, 2015).

Especificando a análise para a temática deste estudo, observa-se que, quanto à judicialização da medicina, devem ser considerados dois contextos concomitantes, hipóteses verificadas nesta tese. 0 primeiro, em que há uma busca assertiva ao Poder Judiciário para a resolução 
de litígios entre médicos e pacientes, como reflexo de um processo de empoderamento dos pacientes que, na medida em que se tornam conhecedores de seus direitos, fazem uso do direito constitucional de ação, provocando o Judiciário na tentativa de resguardo de seus interesses (VASCONCELOS, 2012).

E o segundo, em que há uma busca excessiva ao Poder Judiciário, em uma tentativa de ocupá-lo do encontro de soluções de problemas presentes na relação entre médicos e pacientes a partir da assimetria de poder/saber e as dificuldades no exercício dos discursos tendo em vista falhas no diálogo (VASCONCELOS, 2012), e que poderiam ser enfrentadas de outro modo. Neste segundo sentido, pode-se observar a conformação de demandas judiciais que poderiam ser evitadas a partir da prévia simetralização do discurso entre médicos e pacientes em uma tentativa de diálogo, o que, possivelmente, propiciaria maior compreensão de circunstâncias próprias à medicina, afastadas de qualquer possibilidade de cometimento de erro médico, mas que podem vir a ser judicializadas.

\section{CONSIDERAÇÕES FINAIS: A SUBSTITUIÇÃO QUE POSSI- VELMENTE SE PERFEZ}

Este estudo entendeu a importante percepção de que uma das justificativas para a judicialização da medicina pode apresentar-se como a materialização dos conflitos provenientes da assimetria entre médicos e pacientes no cotidiano, percebida no âmbito dos discursos hierarquizados. E como se trata de atividade em que o diálogo é imprescindível, notou ser necessário aos sujeitos estarem propensos a um diálogo adequado ao esclarecimento e à absorção de informações prévias à conduta médica responsável.

Em uma percepção teórica, considerou também a existência do fenômeno de substituição de poderes, tomando o judicial em detrimento do popular, frente ao médico, atendo-se à percepção de uma possível falência no âmbito dialógico entre médicos e pacientes, concretizada pela manutenção dos sistemas de dominação analisados conforme a teorização foucaultiana, e agravada pela dificultosa realização de direitos fundamentais na prática cotidiana. 
Neste sentido, refletiu que o poder médico vive, neste momento, uma discussão sobre a sua necessária relativização e simetria diante do início do desenvolvimento de um novo poder. Não o do paciente, que teria que se apresentar pela via do empoderamento através do saber, em uma perspectiva foucaultiana. Mas um novo poder provindo da força, em uma perspectiva sponvilliana: e tem-se o paciente substituído pelo Poder Judiciário, o que enseja a ocorrência do fenômeno da Judicialização da Medicina.

Assim sendo, são identificados contextos de pacientes e, ainda, de médicos como sujeitos também passíveis de identificarem-se com o âmbito de menor poder, estes últimos quando em perspectivas institucionais e judicantes. Em outras palavras, compreende-se que a busca por este poder judicial é capaz de dar-se como uma substituição do não-poder do paciente frente ao poder médico existente.

\section{NOTAS}

1 A partir desta teoria, partir-se-á para a compreensão de alguns dos conceitos relacionados com procedimentos apresentados pelo autor, selecionados por dedução teórica tendo em vista as suas aproximações à hipótese deste estudo, que não pretendeu analisar discursos propriamente, mas compreender como se dá sua hierarquização.

2 Além disso, também se apresenta como pertinente, embora não seja o objeto deste estudo, a análise de problemas socioeconômicos cotidianos capazes de promover o acréscimo da assimetria, ou o seu decréscimo.

3 No original: "This technological advance reduced the significance of the patient's narrative. Why should physicians painstakingly acquire this story and its subjective and unverifiable verbal evidence, if they could use more objective sonic evidence they gathered themselves? With the stethoscope, physicians stepped back from the lives of patients. They began to engage patients through the anatomic and physiologic signs detected by their instruments."

4 Atualidade esta relativa ao ano em que discursou, 1991, mas cujo conteúdo pode-se considerar também atual em 2016.

5 Reflexão esta que coaduna com o que Foucault discorre em um dos livros sobre a história da sexualidade, trabalhado por ele como "potência da morte". 


\section{REFERÊNCIAS}

ABBAGNANO, Nicola. Dicionário de filosofia. São Paulo: Martins Fontes, 2012.

BOHÓRQUEZ, Francisco. El diálogo como mediador de la relación medico - paciente. Revista ieRed: Revista Electrónica de la Red de Investigación Educativa [Internet] Vol.1, No.1 (Julio-Diciembre de 2004). Disponível em: <http://revista. iered.org>. Acesso em $11 \mathrm{dez} 2017$

BRASIL. Constituição da República Federativa do Brasil de 1988. Brasília, DF, 1988. Disponível em: http://www.planalto.gov.br/ccivil_03/constituicao/ ConstituicaoCompilado.htm. Acesso em: 11 dez. 2017

BRASIL. Lei no 10.406, de 10 de janeiro de 2002. Institui o Código Civil [Internet]. Brasília, DF, 2002. Disponível em: <http://www.planalto.gov.br/ccivil_03/ leis/2002/L10406.htm>. Acesso em: 11 dez. 2017.

CAMPOS, Roberto Augusto de Carvalho, CAMARGO, Rosmari Aparecida Elias, NEVES, Luciano Rodrigues. The judicialization of the medical act. Braz. j. otorhinolaryngol, $2016 \mathrm{Fev}$ [citado 2017 Mar 20] ; v. 82, n. 1, p. 1-2. Disponível em: <http://www.scielo.br/scielo.php?script=sci_arttext\&pid=S180886942016000100001\&lng=pt. http://dx.doi.org/10.1016/j.bjorl.2015.12.002>. Acesso em: 11 dez. 2017.

CAPRARA, Andrea; FRANCO, Anamélia Lins e Silva. A Relação pacientemédico: para uma humanização da prática médica. Cad. Saúde Pública, Rio de Janeiro, v. 15, n. 3, p. 647-654, set. 1999. Disponível em: <http://www. scielo.br/scielo.php?script=sci_arttext\&pid=S0102-311X1999000300023\&ln g=en\&nrm=iso > . Acesso em: 11 dez. 2017. http://dx.doi.org/10.1590/S0102311X1999000300023.

CAPRARA, Andrea; RODRIGUES, Josiane. A relação assimétrica médico-paciente: repensando o vínculo terapêutico. Ciênc. saúde coletiva, Rio de Janeiro, v. 9, n. 1, p. 139-146, 2004. Disponível em: <http://www.scielo.br/scielo.php?script=sci arttext\&pid=S1413-81232004000100014\&lng=en\&nrm=iso >. Acesso em: 11 dez. 2017. http://dx.doi.org/10.1590/S1413-81232004000100014.

CARNELUTTI, Francesco. Como nasce o direito. São Paulo: Editora Pillares, 2015. 
CHEHUEN NETO, José Antônio; SIMARCO, Mauro Toledo; ROCHA, Flávio Roberto Silva; SOUZA, Camila Freitas de; PEREIRA, Francisca Simões. Confiabilidade no médico relacionada ao pedido de exame complementar. HU rev., Juiz de Fora, v.33, n.3, p.75-80, jul./set. 2007.

COMTE-SPONVILLE, André. Poder e saber: a propósito dos médicos, da tirania e do ridículo. In: Valor e verdade: estudos cínicos. São Paulo: WMF Martins Fontes, 2008.

CUNHA, Antônio Geraldo. Dicionário etimológico da língua portuguesa. Rio de Janeiro: Lexikon, 2010.

DANTAS FILHO, Venâncio Pereira; SÁ, Flávio César de. 0 cuidado na prática médica. 0 Mundo da Saúde, São Paulo, v. 33, n 2, p. 189-194, 2009. Disponível em: < http://www.revistamundodasaude.com.br/index.php/principal/edicoes2>. Acesso em: 11 dez. 2017.

MICHAELIS. Diálogo. Dicionário de Português Online. Disponível em: <http:// michaelis.uol.com.br/moderno-portugues/busca/portugues-brasileiro/ DI\%C3\%81LOGO/>. Acesso em: 11 dez. 2017.

ESTADÃO. SAÚDE. Em 4 anos, número de processos por erro médico cresce $140 \%$ no STJ Entre 2010 e 2014, recursos saltaram de 260 para 626, mostra levantamento obtido com exclusividade pelo "Estado"; no mesmo período, 18 profissionais tiveram registros cassados por conselho. Disponível em: <http://saude.estadao.com.br/noticias/geral,em-4-anos-numero-de-processospor-erro-medico-cresce-140-no-stj-imp-,1655442>. Acesso em: 11 dez. 2017.

FOUCAULT, Michael. Microfísica do poder. Organização e tradução Roberto Machado. Rio de Janeiro: Edições Graal; 1979.

História da sexualidade I: a vontade de saber. Rio de Janeiro: Edições Graal, 1988.

. A ordem do discurso. São Paulo: Edições Loyola, 2009.

GARRAFA, Volnei. Bioética, saúde e cidadania. In: Barchifontaine CP, Pessini L (Orgs.). Bioética: alguns desafios. São Paulo: Edições Loyola, 2001. 
GONTIJO, Guilherme Dias. A judicialização do direito à saúde. RMMG. Minas Gerais, v. 20, n. 4, p. 606-611, 2010. Disponível em: <http://rmmg.org/artigo/ detalhes/345>. Acesso em: $11 \mathrm{dez} .2017$.

JASPERS, Karl. 0 médico na era da técnica. Lisboa, Portugal: Edições 70, 1998.

JONAS, Hans. 0 princípio responsabilidade: ensaio de uma ética para a civilização tecnológica. Rio de janeiro: Contraponto: Ed. PUC-Rio, 2006 apud SCHRAMM, Fermin Roland. 0 poder do diálogo e o engajamento das pessoas comuns. In: Junges JR, Garrafa V. (Org.) Solidariedade crítica e cuidado: reflexões bioéticas. 1. ed. São Paulo: Edições Loyola; Centro Universitário São Camilo, 2011, p. 106.

LÉVINAS, Emmanuel. Dieu, la mort, le temps. Paris: Grasset, 1993 apud SCHRAMM, Fermin Roland. 0 poder do diálogo e o engajamento das pessoas comuns. In: Junges JR, Garrafa V. (Org.) Solidariedade crítica e cuidado: reflexões bioéticas. 1. ed. São Paulo: Edições Loyola; Centro Universitário São Camilo, 2011, p. 106.

LUCENA FILHO, Humberto Lima de. A cultura da litigância e o Poder Judiciário: noções sobre as práticas demandistas a partir da Justiça Brasileira. In: Conselho Nacional de Pesquisa e Pós-Graduação em Direito - CONPEDI. (Org.). Anais do XXI Encontro Nacional do Conselho de Pesquisa e Pós-Graduação em Direito: 'Sistema Jurídico e Direitos fundamentais Individuais e Coletivos'. 56. ed. Florianópolis: Fundação Boiteux, v. 21, p. 34-64, 2012.

MOLIÈRE. O Doente Imaginário. Tradução Daniel Fresnot. 2. ed. São Paulo: Martins Claret, 2003.

OLIVEIRA, Maria dos Remédios Mendes. A judicialização da saúde no Brasil. Tempus Actas de Saúde Coletiva, Brasília, DF, v. 7, n. 1, p. 79-90, abr. 2013. Disponível em: < http://www.tempusactas.unb.br/index.php/tempus/article/ view/1276/1113>. Acesso em: 11 dez. 2017.

OSELKA, Gabriel (Coord.). Atestado médico: prática e ética. São Paulo: Conselho Regional de Medicina do Estado de São Paulo, 2013.

PASCAL, Blaise. Pensamentos. Versão para eBook. 2002. Disponível em: http:// www.ebooksbrasil.org/eLibris/pascal.html\#24. Acesso em: 11 dez. 2017.

. Pensées. Oeuvres completes, Seuil: Lafuma, 1963 apud COMTE-SPON- 
VILLE, André. Poder e saber: a propósito dos médicos, da tirania e do ridículo. In: Valor e verdade: estudos cínicos. São Paulo: WMF Martins Fontes, 2008.

REISER Stanley Joel. History of Medical Technology. In: Post SG, editor in chief. Encyclopedia of bioethics. 3rd ed., vol. 5. New York: Macmillan Reference USA, p. 2497-503, 2004. Disponível em: < http://www.encyclopedia.com/science/ encyclopedias-almanacs-transcripts-and-maps/technology-i-history-medicaltechnology>. Acesso em: 11 dez. 2017.

RODRIGUES, Carlos Frederico Almeida. Considerações éticas sobre a medicina contemporânea: uma reflexão pontual. Revista Bioética, V. 18, n. 2, p. 373-9, 2010. Disponível em: http://revistabioetica.cfm.org.br/index.php/revista_bioetica/article/viewFile/570/542. Acesso em: 11 dez. 2017.

ROUSSEAU, Jean Jacques. 0 contrato social. Porto Alegre: L\&PM, 2009, p. 32-3.

SCHRAMM, Fermin Roland. O poder do diálogo e o engajamento das pessoas comuns. In: Junges JR, Garrafa V. (Org.) Solidariedade crítica e cuidado: reflexões bioéticas. São Paulo: Edições Loyola; Centro Universitário São Camilo, p. 99-107, 2011.

SOARES, Jussara Calmon Reis de Souza; CAMARGO JR., Kenneth Rochel. A autonomia do paciente no processo terapêutico como valor para a saúde. Interface (Botucatu), 2007 abr. [citado 21 abr. 2017], v.11, n. 21, p. 65-78. Disponível em: http://www.scielo.br/scielo.php?script=sci arttext\&pid=S1414-32832007000100007\&lng=pt., http://dx.doi.org/10.1590/ S1414-32832007000100007. Acesso em: 11 dez. 2017

SOURNIA, Jean Charles. História da medicina. Tradução Jorge Domingues Nogueira. Lisboa: Instituto Piaget; 1995.

THEODORO JÚNIOR, Humberto; NUNES, Dierle; BAHIA, Alexandre Melo Franco; PEDRON, Flávio Quinaud. Novo CPC: fundamentos e sistematização. 2. ed. Rio de Janeiro: Forense, 2015.

UNESCO. Declaração Universal dos Direitos Humanos. Adotada e proclamada pela resolução 217 A (III) da Assembléia Geral das Nações Unidas em 10 de dezembro de 1948 [Internet]. [Acesso em 11 dez 2017]. Disponível em: http://unesdoc.unesco.org/images/0013/001394/139423por.pdf. Acesso em: 11 dez. 2017. 
VASCONCELOS, Camila. Responsabilidade médica e judicialização na relação médico-paciente. Rev. Bioética., v. 20, n. 3, p. 389-96, 2012.

Artigo recebido em: 11-12-2017

Aprovado em: 29-1-2018

\section{Camila Vasconcelos}

Doutora em Bioética pela Universidade de Brasília (UNB); mestre em Bioética pela Universidade dos Açores (UAç) e Universidade Católica Portuguesa do Porto (UCP), em Portugal; especialista em Bioética e Biodireito; professora da Faculdade de Medicina da Universidade Federal da Bahia, Departamento de Medicina Preventiva e Social, Eixo Ético-Humanístico; advogada em Direito Médico e Biodireito; integrante do Núcleo Bioética e Ética Médica (NBE-FMBUFBA) e do Grupo de Estudo, Pesquisa e Extensão em Bioética e Ética Médica (GBEM-FMB-UFBA); professora da Pós-graduação lato sensu em Direito Médico da Universidade Católica do Salvador (UCSal). E-mail: camila@cvadv.com.br

Faculdade de Medicina da Universidade Federal da Bahia Rua Reitor Miguel Calmon, s/n - Vale do Canela, Salvador - BA, 40110-100 